\title{
EMPLOYEE ENGAGEMENT: A CRITICAL ANALYSIS BETWEEN JOB SATISFACTION AND ORGANISATION PERFORMANCE
}

\author{
B. VIJAYALAKSHMI ${ }^{1} \&$ G. YAMUNA ${ }^{2}$ \\ ${ }^{1}$ Professor, Department of Business Management, Sri Padmavati Mahila Visvavidyalayam \\ (Women's University), Tirupati, Andhra Pradesh, India \\ ${ }^{2}$ Research Scholar, Department of Business Management, Sri Padmavati Mahila Visvavidyalayam \\ (Women's University), Tirupati, Andhra Pradesh, India
}

\begin{abstract}
In today's scenario economic situations of the company drastically move into upstage as good company suffers more problems one of them is relate to retain the competent employee at the workplace. Whenever the employee should engage in his/her work competently the organisation, retention of the employee rate to be high for achieving career and organisation goals. So that Engaged employee is consists of retaining the best employee. Job satisfaction leads to highly engaged in working environment with the people. To identify and determine the impact of employee engagement on job satisfaction the factors which considers as job nature, priority of superior, team spirit, relationship of colleagues, remuneration, policies of the company how much contribute to the employee engagement in the workplace. The purpose of this paper is to analyze the job satisfaction and organisational performance with the impact of employee engagement. This paper is an attempt through empirical approach towards the study subject and the selected area for the study is IT industry.
\end{abstract}

KEYWORDS: Job Satisfaction, Employee Engagement, Organisation Performance, Retain Employee, Job Nature, Team Spirit, Priority of Superior \& Policies of the Company

JEL Classification: J24, M10, M50

Received: Feb 27, 2019; Accepted: Mar 19, 2019; Published: Mar 28, 2019; Paper Id.: IJHRMRAPR201916

\section{INTRODUCTION}

Human resources are the competent asset in an organisation to achieve maximum results. The role of a manager is to attract, guide and retain the competent employee to improve organisational performance. So that his responsibility is to create a supportive environment for the employees in terms of the nature of the job, career aspirations, remuneration, the best rapport among all levels of workers, company norms and standards etc. To these aspects an employee feels better satisfaction in their job and personal life. If an employee feels more satisfaction in their job they also provide satisfaction to the customers too. In this process of satisfaction to the worker leads to engagement of work in an effective manner. It has been observed by the researcher that highly engaged worker creates a value to the organisation. The Employee engagement refers to as how effectively an employee involves and commitment towards the job has stayed in the long run. Job satisfaction is defined as it's a positive state of employee feels about their job in terms of benefits provided by the organization. 


\section{Employee Engagement vs. Job Satisfaction}

Employee Engagement is a strategic approach in the workplace environment that to be followed by the organisation because it treated the real asset between employees and organisation. An "engaged employee" is treats as the person in the organisation who enthusiastically involve in their work to enhance the reputation of the organisation. The success of an organisation depends on how employees are committed working for achieving organisational goals as well individual motives. In contrast, job satisfaction is the term which is replaced with the term employee engagement. It is regarded as the extent feeling about in his or her job, salary, benefits, etc. The happiest people in the organisation are commonly known as more satisfied employee.

Job Satisfaction is referred as how an organisation creates a positive or negative opinion towards their job environment for employees. The perfect job environment satisfies the worker motives, desires or personal beliefs. It means in which the employees most like their job. The major characteristic of job satisfaction must influence the manager behaviour, culture of organisation, worker commitment, promotion of work position etc. Job satisfaction is the system of gaining appraisal by fulfilling positive emotional state of work.

\section{REVIEW OF LITERATURE}

Thiagarajan B \& Renugadevi V (2011), had done the research title on "An empirical investigation on Employee Engagement Practices in Indian BPO Industries" the objective of this paper is to introduce engagement programme and factors which related to employee engagement in BPO industries in India. The author investigated with sample size of 126 respondents of structured interview basis. In this study, he focuses on the factors like career development, motivation and performance appraisal to concentrate these factors in the organisation must lead to employee engagement. Sakari Taipale, Kirsikka Selander, Timo Anttila, Jouko Nätti (2011), conducted a research titled on "Work engagement in eight European countries: The role of job demands, autonomy, and social support" the major intention of this paper was to determine the new approaches in work engagement and to develop new theories about job demand, autonomy and social support for the achievement of cross national knowledge. He found that there is a lacking of cross national approach to work engagement.

Rehman Muhammad Safdar \& Waheed Ajmal (2011), research conducted on "An Empirical Study of Impact of Job Satisfaction on job Performance in the Public Sector Organizations". The aim of this study was to know the relationship of job satisfaction, job retention and job performance through descriptive correlational study with 568 samples of employees of public sector organisations. He has explained about the relationship of large effect on job performance and job satisfaction. Mamta, Sharma R. Baldev (2011), research title on "Study of Employee Engagement and its Predictors in an Indian Public Sector Undertaking” This paper explores an assessment of employee engagement in public sector managers of India. He has identified that organisational commitment is the factor of employee engagement. In this study he found that three variables greatly affect employee engagement those are salary, job description and objectivity. The results of this study revealed that the organisation achieves a moderate effect on employee engagement.

Sharma Baldev $\mathbf{R}$ et al (2010), studied the title on "Determinants of Employee Engagement in a Private Sector Organization: An Exploratory Study" by using the SPSS package for analysis with a structured questionnaire of 80 items and the study consists of 51 sales executives of a manufacturing organization located in the National Capital Region. The purpose of the study was to determine the level of employee engagement with the sample unit of sales executives of a 
private sector organisation. Sobia Ali \& Yasir Aftab Farooqi (2014) research done on the Effect of Work Overload on Job Satisfaction, Effect of Job Satisfaction on Employee Engagement and Employee Performance" the aim of this paper was to identify the work load and job satisfaction effect and determine the effect of job satisfaction and employee engagement and performance. This study said that work load is the influencing factor for the organisation and it affects job satisfaction, employee engagement and employee performance. He found that peaceful workload and stress are the strategies which consist of training, job rotation. He also recommended that with the use of advanced technology can decrease the work load of employee.

Fachrunnisa Olivia et al (2014) conducted research on the Role of Workplace Spirituality and Employee Engagement to enhance Job Satisfaction and Performance. The aim of the study explains the role of engagement between superior and subordinate to increase job satisfaction and performance. He recommended that work place spirituality and employee engagement should create job satisfaction then it leads to employee performance. Deepa \& Kuppusamy (2014) studied research on the Impact of Performance Appraisal System on Job Satisfaction, Employee Engagement, Organisational Citizenship Behaviour and Productivity. This paper is purely conceptual model it explains the relationship of Job Satisfaction, Organisation Culture, Organisation Citizenship Behaviour, and Employee Engagement and thus leads to performance. The results said that if performance appraisal uses not only employees but also organization to increase productivity. Hence employee once satisfied with the job they involve in the work so that set goals are achieved automatically organisation commitment and citizenship would increase more.

Schreurs. et al (2013) conducted research on a study to explore the relation between Pay-Level Satisfaction and Employee Outcomes: The moderate Effect of Employee-Involvement Climate. This study analyzed the climate of employee engagement as effect of pay, job satisfaction and turnover intentions. This study said that with the increase of pay can lead to high job commitment and job satisfaction. Biswas Soumendu \& Bhatnagar Jyotsna (2013) studied on the title of on the Mediator Analysis of Employee Engagement: Role of Perceived Organisational Support, P-O Fit, Organisational Commitment and Job Satisfaction. This paper explained the role of employee engagement towards job satisfaction and commitment of organisation. This study explores that employee engagement can give creativity in work environment.

Henryhand J. Carla (2009) had done the research on a study The Effect of Employee Recognition and Employee Engagement on Job Satisfaction and Intent to leave in the Public Sector. This study focused on the impact of job satisfaction towards the effectiveness of employee engagement and recognition. This study revealed that to retain the employee can possible only through recognition and commitment of the employee.

\section{OBJECTIVES OF THE STUDY}

- To study the impact of Job satisfaction on Employee Engagement

- To analyze the effect of employee engagement that leads to job satisfaction and organisational performance.

- To understand the relationship of the level of employee engagement on job satisfaction.

- To determine the relationship between employee engagement and organisation performance. 


\section{METHODOLOGY}

A structured questionnaire was distributed to the sample of 234 IT professionals in Chennai that are working for an IT companies since from long back. Since the present study was descriptive with set objectives which are framed through the literature gap identification process, the research design was descriptive research design. Through a lottery method, the simple random sampling technique was selected as a sampling technique and the sample size was determined using population variance, margin of error 5 percent and $\mathrm{Z}$ score 1.96 obtained after pilot study with 50 random samples. Both methods like primary and secondary data were used to collect data. Descriptive statistics and inferential statistics were applied by using excel and SPSS 21.0 version. Variable reliability and validity was tested using standardized methods. Likert 5.0 rating scale was administered as a scaling method of questionnaire.

\section{Hypothesis}

- Employee Engagement will significantly influenced by employee job satisfaction

- Organizational Performance will be influenced by the employee job engagement

\section{DATA ANALYSIS AND INTERPRETATION}

\section{Descriptive Results}

The initial information about respondents demographic details were presented in the table $\mathbf{1}$ hence the details in order like 166/234 male respondents participated in the survey, 108/234 surveyed IT professional are in the age group of 25 to 30 years, 74/234 respondents have been into IT industry with more than 7 years and above, 80 percent of total sample are earning an annual income of 6 to 8 lacs package per annum (Income variable). Around 56 percent of respondents are unmarried but not they are majority in the sample since married are nearly 46 percent.

Table 1: Demographic Details of Sample

\begin{tabular}{|c|c|c|c|}
\hline Sl. No & Demographic & Labels & $\begin{array}{c}\text { Total } \\
\text { Number/234 }\end{array}$ \\
\hline \multirow{2}{*}{1} & \multirow{2}{*}{ Gender } & Male & 166 \\
\hline & & Female & 68 \\
\hline \multirow{5}{*}{2} & \multirow{5}{*}{ Age } & 20-22 years & 13 \\
\hline & & 22-24 years & 22 \\
\hline & & 24-26 years & 25 \\
\hline & & $26-28$ years & 108 \\
\hline & & Above 28 years & 66 \\
\hline \multirow{5}{*}{3} & \multirow{5}{*}{ Experience } & Less than 1 year & 23 \\
\hline & & $1-3$ years & 18 \\
\hline & & $3-5$ years & 52 \\
\hline & & $5-7$ years & 67 \\
\hline & & Above 7 years & 74 \\
\hline \multirow{5}{*}{4} & \multirow{5}{*}{ Income } & Less than 2 lacs & 29 \\
\hline & & 2-4 lacs & 43 \\
\hline & & 4-6 lacs & 32 \\
\hline & & 6-8 lacs & 85 \\
\hline & & Above 8 lacs & 45 \\
\hline \multirow{2}{*}{5} & \multirow{2}{*}{$\begin{array}{l}\text { Marital } \\
\text { details }\end{array}$} & Married & 46 \\
\hline & & Unmarried & 54 \\
\hline
\end{tabular}




\section{Mean and S.D, Normality Test Results}

The mean responses given by sample respondents on the 5.0 rating scale that was labeled as 1.0-strongly disagree to 5.0 strongly agree of each measured items was shown in the Table 2 along with its standard deviation. There were three constructs described as Employee Engagement (EE), Organizational Performance (OP) and Job Satisfaction (JS) used in the present study. The mean agreeability of the respondents on each construct based according to its underlined dimensional item was like in the range of $(\mu=3.2 ; \sigma=0.01$ to $\mu=3.26 ; \sigma=1.02)$ for Employee Engagement, Organizational Performance $(\mu=3.34 ; \sigma=0.34$ to $\mu=3.89 ; \sigma=0.98)$ and for Job Satisfaction the mean scores were in the range of $(\mu=3.1 ; \sigma=0.24$ to $\mu=3.68 ; \sigma=0.99)$.

To confirm the issue of non normality of the data, a suggested test of normality Shapiro-wilk test was run and its resulted that are shown in the below tables shows that there was no issue of non normality in the data since all the dimensional Shapiro-wilk test was no significant hence the alternative hypothesis that there is a issue of normality has been rejected at 5 percent level of significance.

Table 2: Mean and S.D, Normality Test Results

\begin{tabular}{|c|c|c|c|c|c|c|}
\hline $\begin{array}{l}\text { Sl. } \\
\text { No }\end{array}$ & Constructs & Dimensions & Mean & S.D & $\begin{array}{c}\text { Shapiro- } \\
\text { Wilk } \\
\text { Normality } \\
\text { Test }\end{array}$ & $\begin{array}{c}\text { Reliability } \\
\text { Statistics } \\
\text { (Cronbach's } \alpha \\
\text { Value) }\end{array}$ \\
\hline \multirow{4}{*}{1} & \multirow{4}{*}{$\begin{array}{l}\text { Employee } \\
\text { Engagement } \\
(\mathrm{EE})\end{array}$} & Job design & 3.1966 & 0.31 & 0.231 & 0.723 \\
\hline & & Culture & 3.2564 & 1.02 & 0.342 & 0.788 \\
\hline & & Recognition & 3.1992 & 0.01 & 0.878 & 0.792 \\
\hline & & Communication & 3.1966 & 0.31 & 0.765 & 0.802 \\
\hline \multirow{4}{*}{2} & \multirow{4}{*}{$\begin{array}{l}\text { Organizational } \\
\text { Performance } \\
\text { (OP) }\end{array}$} & Improved Profits & 3.1966 & 0.56 & 0.432 & 0.812 \\
\hline & & Improved bottom line & 3.8776 & 0.98 & 0.666 & 0.785 \\
\hline & & Improved productivity & 3.3376 & 0.34 & 0.543 & 0.834 \\
\hline & & Employee proactive & 3.2393 & 0.89 & 0.422 & 0.856 \\
\hline \multirow{4}{*}{3} & \multirow{4}{*}{$\begin{array}{l}\text { Job } \\
\text { satisfaction } \\
\text { (JS) }\end{array}$} & opportunity for advancement & 3.6782 & 0.99 & 0.982 & 0.890 \\
\hline & & career aspirations & 3.2393 & 0.76 & 0.765 & 0.843 \\
\hline & & feelings of compensation fairness & 3.0897 & 0.23 & 0.987 & 0.901 \\
\hline & & supervisor relations & 3.0299 & 0.24 & 0.321 & 0.911 \\
\hline
\end{tabular}

\section{Inferential Results through ANOVA and Correlation}

The test result of one way ANOVA and bivariate Pearson correlation coefficient was presented in the Table 3 below. Employee Engagement, Organizational Performance and Job Satisfaction were positively high correlated with each other (Between EE and OP: r: 0.921: p=0.000<0.05), between EE and JS (r: 0.966: p=0.000<0.05) and between OP and JS r: 0.978: $\mathrm{p}=0.000<0.05)$. Hence all the selected three constructs are in high linear relational. Employee Engagement as a dependent variable, there exist a significant impact of Organizational performance and job satisfaction on it since the $\mathrm{F}$ score between $\mathrm{EE}$ and $\mathrm{OP}$ is $\mathrm{F}_{233}=270.978$, Sig. $\mathrm{P}$ value is $0.000<0.05$ and between $\mathrm{EE}$ and $\mathrm{JS}$ is $\mathrm{F}_{233}=845.215$, Sig. $\mathrm{P}$ value is $0.000<0.05$.

Table 3: Correlation and ANOVA

\begin{tabular}{|c|c|c|c|c|c|c|}
\hline Sl. No & Variable & Empl.Eng.(EE) & Org.Perf.(OP) & Job. Sat.(JS) & F- Value & Sig. \\
\hline 1 & Empl.Eng.(EE) & - & & & & \\
\hline 2 & Org.Perf.(OP) & $0.921^{* * *}$ & - & & 270.978 & $0.000^{* * *}$ \\
\hline 3 & Job. Sat.(JS) & $0.966^{* * *}$ & $0.978^{* * *}$ & - & 845.215 & $0.000^{* * *}$ \\
\hline
\end{tabular}

*** Significant @5 percent level, Empl. Eng. (EE): Employee Engagement, Org. Perf. (OP): Organizational Performance, Job. Sat. (JS): Job Satisfaction 


\section{CHAID Regression Tree ob Employee Engagement and Job Satisfaction}

Since it was a popular method of predictive analysis called Chi Squared Automatic Interaction Detection and regression analysis that predicts the value of the target groups. The below decision tree projects the categorical grouping of respondents who have got different levels of satisfaction by their engagement in the job as an employee. There are three nodes produced by job satisfaction that influences employee engagement. These nodes were framed based on predicted mean value of each group. Node-1 represents the group of equal to or less than the mean response of 3.750(Mean=2.097, $\mathrm{S} . \mathrm{D}=0.820, \mathrm{n}=118, \%=50.4)$. Node -2 represents the group of between 3.750 and 4.00 rating of the mean response of 3.750(Mean $=4.00, S . D=0.00, n=62, \%=26.5$ ) and Node-3 represents the group of equal to or greater than the mean response of 4.00 (Mean=4.741, S.D=0.442, $\mathrm{n}=54, \%=23.1$ ). This Chi squared automatic interaction detection regression analysis is significant at 1 percent level of significance between employee engagement and job satisfaction as the $\mathrm{F}$ Statistic is $\left.\mathrm{F}_{2,231}\right)=403.399$; Sig.P $=0.00 .<0.05$.

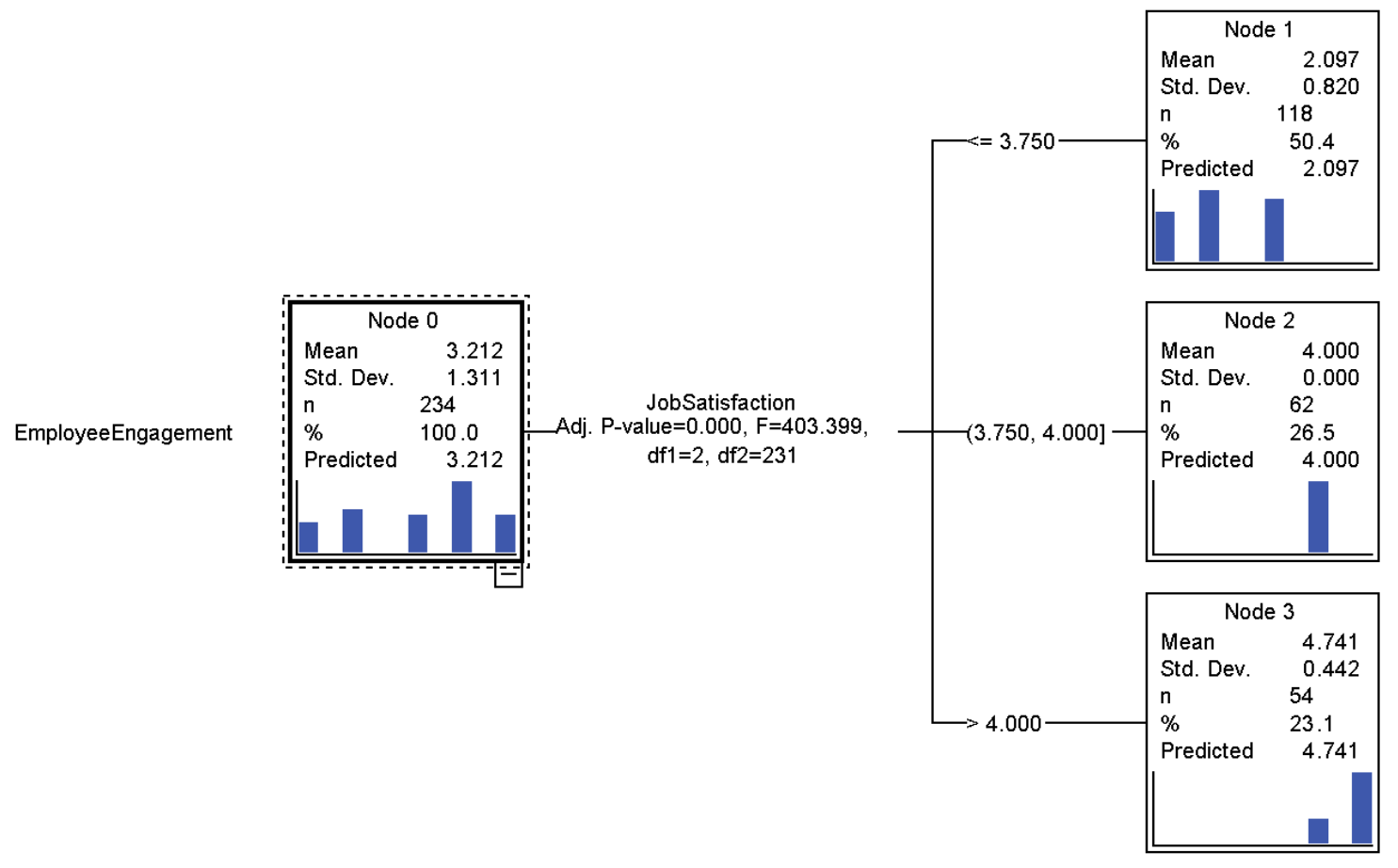

Diagram 1: Decision Tree of Employee Engagement and Job Satisfaction

In continuation to the above decision tree, the given below graph projects the mean percentile of the groups. 20 percent of the total sample has a high job satisfaction regarding their job engagement (Mean=4.741). 30 percent of the group also has high job satisfaction depending on employee engagement (Mean=4.570), alike this up to 50 percent of the sample groups of the decision tree are highly depending on job satisfaction based job engagement. Remaining 50 percent of the groups are moderately depending on job satisfaction based employee engagement since the Mean score of 3.95 to 3.21 range is been observed from the below graph. 


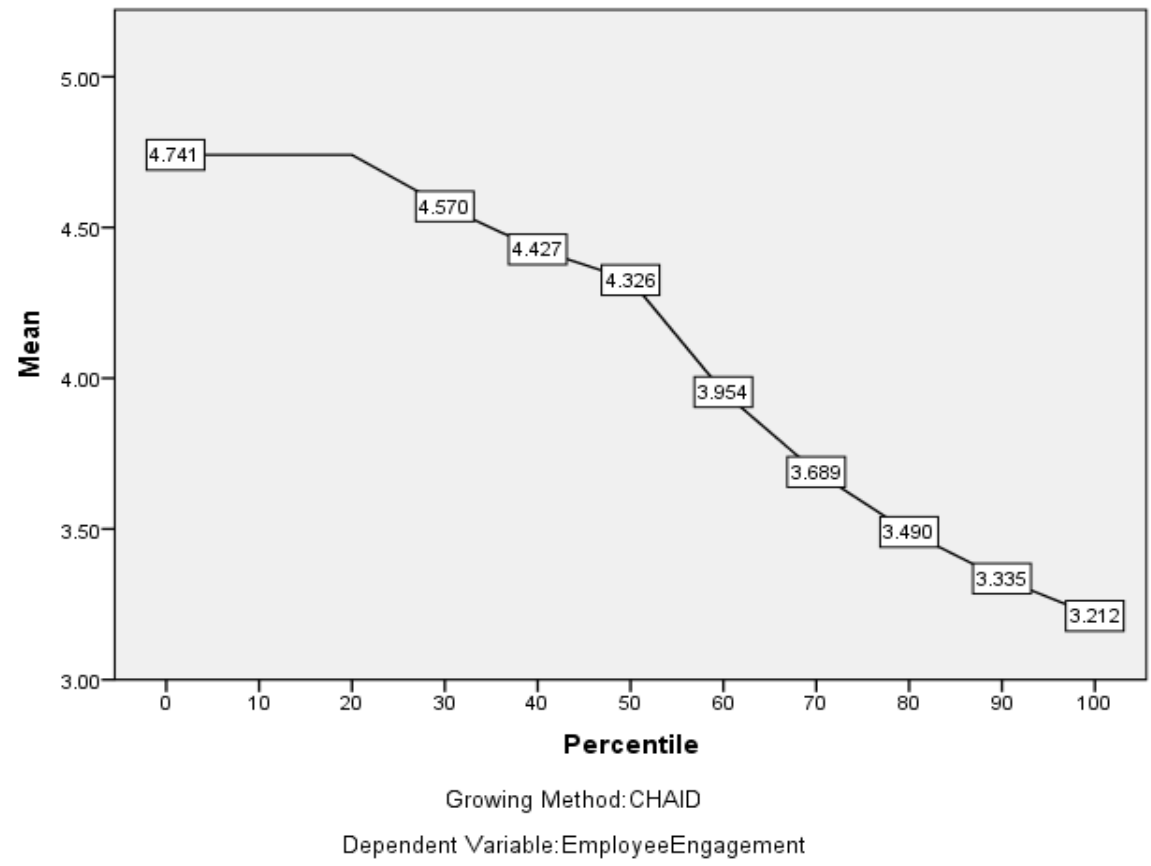

Graph 1: Mean of Groups by Its Percentile

\section{FINDINGS AND SUGGESTIONS}

The key findings founded from the present study are as follows that there is a strong high positive linear relationship existed between employee engagement and job satisfaction and organizational performance. Furthermore the study tried to classify the sample as groups that are categorized in number three based on high, moderate and low levels of regression association between the latent and manifest variable. Thus, it was found employee engagement has shown high depends on job satisfaction since the nodes in decision trees under this are in above a moderate level of acceptance. All together, employee engagement in relation to job satisfaction was notable high as 50 percent of the group are rated this relationship significantly at high rate of mean responses. Organizational performance of an employee that influences employee work engagement was also significant with high rate of group mean. Employee engagement at work or a job would definitely influence the level of job satisfaction and leads to organizational better performance. The key suggestion is made on the basis of these findings such that more strategic employee work engagement has to be evaluated by topping the priority of job satisfaction and organizational performance in term of reaching the desired outcomes of the organization objectives. When an employee finds they are not satisfied in their roles, they could not able engage well and good at their job, hence as a consequence to this, organization performance may affect negatively. Management practionaries are recommended from this study to make better strategies at work place keeping in mind there would be a high string positive relationship exists between employee engagement, job satisfaction and organizational performance.

\section{LIMITATION AND FUTURE RESEARCH SCOPE}

Although the present study tried to measure certain critical aspects of employee engagement relating job satisfaction and organizational performance, it has definite limitation such as no model approached measurement was studied. That the sample size was 234 IT Professional in Chennai only is also a limitation of the study. So, I had to confine to the voluntary participation within the limits of the study and IT professionals where homogeneity could create some bias in generalizing the findings to other industry. Future research could be taken up by measuring the mediating or moderating 
relationship of employee engagement, job satisfaction and organizational performance due to emerge of applying sophisticated statistical methods called mediation and moderation.

\section{CONCLUSIONS}

As revealed by earlier research studies, employee engagement at work could be a driving force of employee job satisfaction thus a lead to better organizational performance in term of reaching the aimed goals. The more employee engagement is applicable the high job satisfaction and performance of organization is guaranteed. The present study is an attempt to evaluate the critical relationship between these factors and hence it was proved that employee engagement is high positively depending on job satisfaction and organizational performance.

\section{REFERENCES}

1. Ali Sobia, Farooqi Aftab Yasir (2014). "Effect of Work Overload on Job Satisfaction, Effect of Job Satisfaction on Employee Performance and Employee Engagement (A Case of Public Sector University of Gujranwala Division)”, International Journal of Multidisciplinary Sciences and Engineering, Vol. 5 (8), pp 23-20.

2. Biswas Soumendu, Bhatnagar Jyotsna (2013). "Mediator Analysis of Employee Engagement: Role of Perceived Organisational Support, P-O Fit, Organisational Commitment and Job Satisfaction”, Vol. 38 (1), pp 27-46.

3. Daiwatabai, D., \& Anandhalli, G. (2018). Job Satisfaction of Library Professionals in Gulbarga and Yadgir Districts of Hyderabad Karnataka Region.

4. Deepa.E, Kuppusamy.S (2014). "Impact of Performance Appraisal System on Job Satisfaction, Employee Engagement, Organisational Citizenship Behaviour and Productivity”, Indian Journal of Applied Research, Vol. 4 (2), pp 4-6.

5. Ellickson, M. (2002). Determinants of job satisfaction of municipal employees. Public Personnel Management, 31(3), pp. 343358.

6. Fachrunnisa Olivia, Adhiatma Ardian, Mutamimah (2014). "The Role of Work Place Spirituality and Employee Engagement to Enhance Job Satisfaction and Performance”, The International Journal of Organisational Innovation, Vol. 7 (1), pp 15-35.

7. Frank, F.D., Finnegan, R.P. and Taylor, C.R. (2004) 'The race for talent: retaining and engaging workers in the 21 st century', Human Resource Planning, 27(3), pp. 12-25.

8. Gallup (2005) Employee engagement index survey, Gallup Management Journal http:suite101.com/article/what-is-an-engaged employee- a214893\#1xzz20NoBcpwi

9. Hayes, Theodore L. (2002), Business unit- level Relationship between Employee Satisfaction, Employee Engagement, and Business Outcomes: A Meta-analysis, Journal of Applied Psychology. 87(2), pp. 268-79.

10. Kahn, W. A. (1990), “An Exercise of Authority”, Organizational Behavior Teaching Review, 4 (2), pp. $28-42$

11. Kaur, S., Singh, S., \& Bhatia, B. Exploring Relationship Among Spiritual Quotient, Feeling Of Oneness And Job Satisfaction Of Employees: An Empirical Study.

12. Henryhand. J. Carla (2009). "The Effect of Employee Recognition and Employee Engagement on Job Satisfaction and Intent to Leave in the Public Sector", Vol. 24 (3), pp 1-130.

13. Lai, S. (2016). Social Integration and Job Satisfaction of Employees With Disability: Comparing and Contrasting With General Newcomers.

14. Locke, E.A. \& D. Henne (1986). Work motivation theories. In C.L. Cooper \& I. Robertson (Eds.) International review of 
industrial and organizational psychology,. London: Wiley. pp. 1-35

15. Mamta \& R. Baldev (2011) Study of Employee Engagement and its Predictors in an Indian Sec-tor. Journal of Service Marketing, Vol. 25, Issue 7, pp-201.

16. Rehman, M.S \& Waheed Ajmal (2011) An Empirical Study of Impact of Job Satisfaction on job Performance in the Public Sector Organizations. Interdisciplinary Journal of Contemporary Re-search in Business, Vol. 2, Issue 9, pp.167-181.

17. Sakari, T et al (2011) Work engagement in eight European countries: The role of job demands, autonomy, and social support. International Journal of Sociology and Social Policy, Volume: 31, pp.78-94.

18. Schreurs. B Bert, Guenter. H Hannes, Schumacher Desiree, Emmerik.V. Hetty, Notelaers (2013). "Pay-Level Satisfaction and Employee Outcomes: The Moderating Effect of Employee Involvement Climate”, Human Resource Management, Vol. 52 5(3), pp 399-421.

19. Sharma, Baldev. $R$ et al (2010) Determinants of Employee Engagement in a Private Sector Organization: An Exploratory Study, Advances in Management, Vol. 3, Issue 10, pp.52-59.

20. Thiagarajan, B \& Renugadevi, V (2011) Employee Engagement Practices in Indian BPO Indus-tries-An Empirical Investigation. Interdisciplinary Journal of Contemporary Research in Business, Vol.2, Issue 10, pp.134-141.

\section{APPENDIX}

Limitations of the Study and Scope for Further Research No work is without precincts, because margins open the way for further growth. This study also engrosses certain limitations. Human behavior is often accepted as a combination of certain personal attributes and various aspects of the situation within which the person is placed. Researchers have, in the past, identified a variety of situational variables that are found to influence behavior. However, when it comes to choosing personal attributes as the potential drivers of behavior, the variables selected are mostly those related to a person's demographic background. The present study was limited to demographic background only. There is potential to do future research in this area. That the sample size was 240 respondents because of the lack of support from the sample frame is also a limitation of the study. So, I had to confine to the voluntary participation within the limits of the study. Size of the sample is also a constraint as it could have been bigger if support was received from the sample frame. Loss of sample also took place because of the incomplete questionnaires. Another limitation of this study pertains to the cross section of the population, which is limited to public and private sector employees. In any case, the findings of this study are indeed relevant to the organizational context. 
